\title{
Opções de tratamento cirúrgico em lesões cutâneas por extravasamento acidental de drogas: experiência do Hospital das Clínicas da Faculdade de Medicina da USP.
}

\section{Surgical treatment of extravasation injuries: experience of the Hospital das Clínicas, Faculty of Medicine, University of São Paulo.}

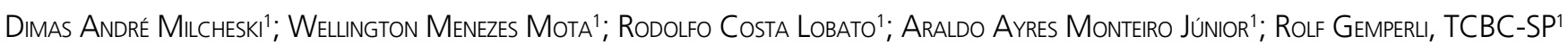

\author{
R E S U M O
}

\begin{abstract}
Objetivo: relatar a experiência da Divisão de Cirurgia Plástica do Hospital das Clínicas da Faculdade de Medicina da Universidade de São Paulo no tratamento de lesões cutâneas por extravasamento acidental de drogas. Métodos: foram incluídos os pacientes com lesões por extravasamento de drogas num período de 18 meses. Os seguintes parâmetros foram avaliados retrospectivamente: idade, diagnósticos durante internação e comorbidades, níveis séricos de albumina e hemoglobina, local de internação, droga envolvida, segmento anatômico acometido, conduta terapêutica e óbito durante internação. Resultados: foram acompanhados 14 pacientes. A principal droga envolvida foi a noradrenalina $(21 \%)$. Todos os pacientes foram submetidos a desbridamento da necrose tecidual. Três pacientes foram submetidos a retalhos após preparo do leito com terapia por pressão negativa, com bons resultados. Sete pacientes não tiveram tratamento definitivo de suas lesões por falta de condições clínicas. Conclusão: o tratamento definitivo por meio de retalhos se mostrou adequado para os casos de feridas por extravasamento de drogas em tecido subcutâneo, quando há exposição de estruturas nobres, em pacientes com condições clínicas favoráveis.
\end{abstract}

Descritores: Doença iatrogênica. Extravasamento de Materiais Terapêuticos e Diagnósticos. Isquemia. Necrose. Retalhos Cirúrgicos. Cirurgia Plástica.

\section{INTRODUÇÃO}

$\Lambda_{\text {a lesões por extravasamento de drogas são }}^{\text {maior causa de morbidade iatrogênica no }}$ ambiente hospitalar ${ }^{1}$. A incidência de tal evento varia na literatura entre $0,1 \%$ e $6 \%$ em pacientes adultos e chegam a variar de $11 \%$ a $70 \%$ em pacientes pediátricos ${ }^{2,3}$. Estão sob maior risco de lesões por extravasamento os pacientes em extremos de idade, neonatos e idosos, além de pacientes com alterações de nível de consciência ou sedados, os quais são incapazes de expressar dor ${ }^{4}$.

Trata-se de um evento que gera alto custo para o sistema de saúde, envolvendo despesas em torno de U\$.66.000,00 por processo nos Estados Unidos $^{5}$. Em até $25 \%$ dos casos de lesão por extravasamento de drogas, a morbidade decorrente do extravasamento é mais grave do que a causa base da internação do paciente. Isso se dá devido à dor, dificuldade de mobilidade, limitação das atividades diárias, lesão nervosa permanente, perda de membros e, em alguns casos, óbito'.

A ocorrência dessas lesões pode ser evitada por meio de medidas preventivas, entretanto, quando ocorrem, necessitam rápido reconhecimento do evento e tratamento adequado imediato de forma a evitar a progressão. O retardo no reconhecimento da lesão pode gerar consequências catastróficas, desde cicatrizes inestéticas, contraturas, celulite, necessidade de enxertos e retalhos cutâneos, lesão neurovascular, encurtamento de membro, amputações e até morte ${ }^{6}$.

Este trabalho tem como objetivo relatar a experiência da Divisão de Cirurgia Plástica do Hospital das Clínicas da Faculdade de Medicina da Universidade de São Paulo (HC-FMUSP) no tratamento de lesões cutâneas por extravasamento acidental de drogas.

1 - Faculdade de Medicina da Universidade de São Paulo, Disciplina de Cirurgia Plástica, Hospital das Clínicas, São Paulo, SP, Brasil. 


\section{MÉTODOS}

Trata-se de um estudo retrospectivo e descritivo, do tipo série de casos, no qual foram avaliados todos os pedidos de interconsulta para o grupo de feridas da Divisão de Cirurgia Plástica do HC-FMUSP no período de janeiro de 2016 a junho de 2017 (18 meses). Todos os pacientes que apresentavam ferida decorrente de extravasamento extravascular inadvertido de medicação nesse período foram incluídos no estudo.

Na casuística estudada, foram analisados os seguintes parâmetros: idade do paciente no momento do evento; diagnósticos durante internação e comorbidades; níveis séricos de albumina e hemoglobina; local de internação - unidade de terapia intensiva ou enfermaria; droga envolvida; segmento anatômico envolvido; conduta terapêutica quanto à ferida; ocorrência de óbito durante internação.

Foi realizada análise descritiva dos dados através do programa Statistical Package for the Social Sciences, versão 18.0 (SPSS Inc., Chicago, IL, EUA). As variáveis categóricas foram descritas mediante porcentagens e as variáveis contínuas por meio de média e desvio padrão da média, se sua distribuição é normal, ou como mediana e intervalo interquartil, em caso de distribuição anormal.

Este trabalho foi aprovado pelo Comitê de Ética da instituição sob o no 76201617.6.0000.0068.

\section{RESULTADOS}

No período do estudo foram analisados 830 pedidos de avaliação de feridas no complexo do HC-FMUSP gerados para a Cirurgia Plástica, totalizando 14 pacientes com ferimentos decorrentes de extravasamento extravascular de drogas, com incidência, em nossa casuística, de 1,6\% das feridas acompanhadas pelo Grupo de Feridas da Cirurgia Plástica.
A média de idade dos pacientes analisados era de 44,4 $\pm 30,2$ anos, variando de um mês a 69 anos. Todos os pacientes estudados tinham ao menos duas comorbidades associadas, as quais podem ser observadas na tabela 1. A localização anatômica mais envolvida foi o dorso da mão (50\%), com ocorrência de lesões cutâneas de espessura total e sem a presença de sinais infecciosos. Os pacientes estavam em tratamento em unidade de terapia intensiva na maior parte dos casos (78,5\%) e 57,1\% evoluiu para óbito durante a internação devido à piora clínica decorrente das comorbidades. Em nenhum caso o óbito foi devido à complicações da ferida. A principal droga responsável pelos incidentes foi a noradrenalina (21\%) administrada em veia periférica em dois casos. Em seis casos, não foi possível a identificação do agente envolvido.

O principal tratamento realizado foi o desbridamento de tecido necrótico, no leito, e curativos diários associados a desbridante químico com alginato de cálcio ou papaína a 10\%, em 11 casos $(78,5 \%)$, devido à condições hemodinâmicas que impediam realização de procedimentos cirúrgicos definitivos. Destes, oito morreram sem que pudesse ser feita a cobertura cutânea definitiva. Os outros três que sobreviveram e não foram submetidos à realização de retalhos eram pacientes pediátricos, os quais apresentaram boa evolução e cicatrização da ferida com o tratamento conservador com os curativos instituídos (Tabela 2).

Três pacientes foram submetidos a fechamento da ferida por meio de retalhos. Todos apresentavam estabilidade hemodinâmica e foram desbridados em centro cirúrgico com preparo do leito com terapia por pressão negativa, além de melhora nutricional, acompanhada pelo aumento do nível sérico de albumina. Uma das pacientes apresentava lesão extensa em mão e antebraço por sacarato 
Tabela 1. Características clínicas dos pacientes e etiologia das lesões.

\begin{tabular}{|c|c|c|c|c|c|c|}
\hline Paciente & $\begin{array}{l}\text { Idade } \\
\text { (anos) }\end{array}$ & Droga & Local & Comorbidades & $\begin{array}{c}\text { Local de } \\
\text { internação }\end{array}$ & Óbito \\
\hline 1 & 54 & Glicose 50\% & Pé direito & $\begin{array}{c}\text { Pós-operatório de tumor } \\
\text { de tronco cerebral + AVC } \\
\text { isquêmico + choque séptico } \\
\text { urinário + BCP }\end{array}$ & UTI & Sim \\
\hline 2 & 1 mês & Bicarbonato & Mão direita & $\begin{array}{l}\text { IRA - diálise peritoneal + } \\
\text { cardiopatia congênita + ICC }\end{array}$ & UTI & Sim \\
\hline 3 & 85 & Noradrenalina & $\begin{array}{l}\text { Antebraço } \\
\text { esquerdo }\end{array}$ & ICC + choque cardiogenico + IRA & UTI & Sim \\
\hline 4 & 8 meses & Desconhecida & Mão direita & $\begin{array}{l}\text { Tetralogia de fallot + ânus } \\
\text { imperfurado }\end{array}$ & Enfermaria & Não \\
\hline 5 & 51 & Desconhecida & Mão direita & $\begin{array}{l}\mathrm{IRC}+\text { marcapasso + colite } \\
\text { isquêmica }\end{array}$ & UTI & Sim \\
\hline 6 & 1 mês & Bicarbonato & Mão direita & Prematuro & UTI & Não \\
\hline 7 & 65 & Desconhecida & Mão direita & $\begin{array}{l}\text { Pós-operatório de transplante } \\
\text { renal + sepse de foco urinário }\end{array}$ & UTI & Sim \\
\hline 8 & 51 & Noradrenalina & $\begin{array}{l}\text { Antebraço } \\
\text { esquerdo }\end{array}$ & $\begin{array}{c}\text { Trauma raquimedular + sepse } \\
\text { de foco urinário + IRA }\end{array}$ & UTI & Sim \\
\hline 9 & 59 & Desconhecida & $\begin{array}{l}\text { Antebraço } \\
\text { esquerdo }\end{array}$ & Abscesso pélvico + choque séptico & UTI & Sim \\
\hline 10 & 65 & Glicose $50 \%$ & Pé esquerdo & $\begin{array}{l}\text { Pós-operatório de transplante } \\
\text { hepático + colangite isquêmica } \\
\text { + sepse de foco pulmonar + } \\
\text { rejeição ao transplante }\end{array}$ & UTI & Sim \\
\hline 11 & 56 & Noradrenalina & Inguinal direita & $\begin{array}{c}\text { IRC + miocardiopatia isquemica } \\
+ \text { DM + HAS }\end{array}$ & UTI & Não \\
\hline 12 & 3 meses & Desconhecida & $\begin{array}{c}\text { Antebraço } \\
\text { direito }\end{array}$ & $\begin{array}{c}\text { Tetralogia de fallot + } \\
\text { endocardite + AVC isquêmico }\end{array}$ & UTI & Não \\
\hline 13 & 69 & Desconhecida & Mão direita & $\begin{array}{c}\text { IRC + pós-operatório de } \\
\text { transplante renal + HAS + sepse } \\
\text { de foco urinário }\end{array}$ & Enfermaria & Não \\
\hline 14 & 66 & $\begin{array}{l}\text { Sacarato de } \\
\text { hidróxido } \\
\text { de ferro III }\end{array}$ & $\begin{array}{l}\text { Mão e } \\
\text { antebraço } \\
\text { direito }\end{array}$ & $\begin{array}{c}\text { IRC + pós-operatório de } \\
\text { transplante renal + pancitopenia } \\
+ \text { infeccção por parvovírus e } \\
\text { citomegalovirus ativa }\end{array}$ & Enfermaria & Não \\
\hline
\end{tabular}

BCP: Broncopneumonia; UTI: Unidade de Terapia Intensiva; IRA: Insuficiência Renal Aguda; ICC: Insuficiência Cardíaca Congestiva; IRC: Insuficiência Renal Crônica; DM: Diabetes Mellitus; HAS: Hipertensão Arterial Sistêmica. 
Tabela 2. Tipo de tratamento estabelecido e parâmetros nutricionais dos pacientes (níveis de albumina e hemoglobina)

\begin{tabular}{|c|c|c|c|}
\hline Paciente & Tratamento & $\begin{array}{c}\text { Albumina } \\
(\mathrm{g} / \mathrm{dl})\end{array}$ & $\begin{array}{c}\text { Hemoglobina } \\
(\mathrm{g} / \mathrm{dl})\end{array}$ \\
\hline 1 & Debridamento no leito + curativo (papaína 10\%) & 2,6 & 8,6 \\
\hline 2 & $\begin{array}{c}\text { Debridamento no leito + curativo } \\
\left.\text { (alginato de cálcio e sódio - hidroge }{ }^{\circledR}\right) \rightarrow \text { cicatrização }\end{array}$ & 3 & 12,7 \\
\hline 3 & Curativos (emolientes) & 2,9 & 13,7 \\
\hline 4 & $\begin{array}{c}\text { Debridamento no leito + curativo } \\
\text { (alginato de cálcio e sódio - hidroge }\left.\right|^{\circledR} \text { ) } \rightarrow \text { cicatrização }\end{array}$ & 3,1 & 13,6 \\
\hline 5 & Debridamento no leito + curativo (papaína 10\%) & 1,5 & 8,8 \\
\hline 6 & $\begin{array}{c}\text { Debridamento no leito + curativo } \\
\text { (alginato de cálcio e sódio - hidroge }{ }^{\circledR} \text { ) } \rightarrow \text { cicatrização }\end{array}$ & 3,3 & 11,6 \\
\hline 7 & Curativo com silicone suave com prata (mepilex ag ${ }^{\circledR}$ ) & 2,7 & 11,7 \\
\hline 8 & Debridamento no leito + curativo (papaína 10\%) & 1,6 & 9,2 \\
\hline 9 & Debridamento no leito + curativo (papaína 10\%) & 1,6 & 7 \\
\hline 10 & Debridamento no leito + curativo (papaína 10\%) & 1,6 & 6,3 \\
\hline 11 & $\begin{array}{l}\text { Debridamento + terapia por pressão negativa (vácuo) } \rightarrow \text { retalho } \\
\text { (tensor da fáscia lata) }\end{array}$ & 3 & 7,7 \\
\hline 12 & $\begin{array}{c}\text { Debridamento no leito + curativo } \\
\left(\text { alginato de cálcio e sódio - hidrogel }{ }^{\circledR}\right) \rightarrow \text { cicatrização }\end{array}$ & 5,7 & 14,2 \\
\hline 13 & Debridamento + retalho local romboide & 2,3 & 7,8 \\
\hline 14 & $\begin{array}{c}\text { Debridamento + terapia por pressão negativa (vácuo) } \rightarrow \text { retalho } \\
\text { (groin flap- mão) e enxertia (antebraco) }\end{array}$ & 2,6 & 10,2 \\
\hline
\end{tabular}

de hidróxido de ferro III (Figura 1). O tratamento inicialmente adotado foi o desbridamento cirúrgico e terapia por pressão negativa, seguido de duas trocas, com evolução para um leito adequado. Nesse momento foi realizado um retalho inguinal baseado na artéria circunflexa ilíaca superficial (groin flap) pediculado para cobertura do dorso da mão direita (Figura 2) e enxertia em antebraço, obtendo-se excelente resultado estético e funcional (Figura 3).

O segundo caso de ferida por extravasamento de noradrenalina em região inguinal direita foi resolvido por meio de retalho tensor da fáscia lata, devido à presença de estruturas nobres em região inguinal, após sete dias com terapia por

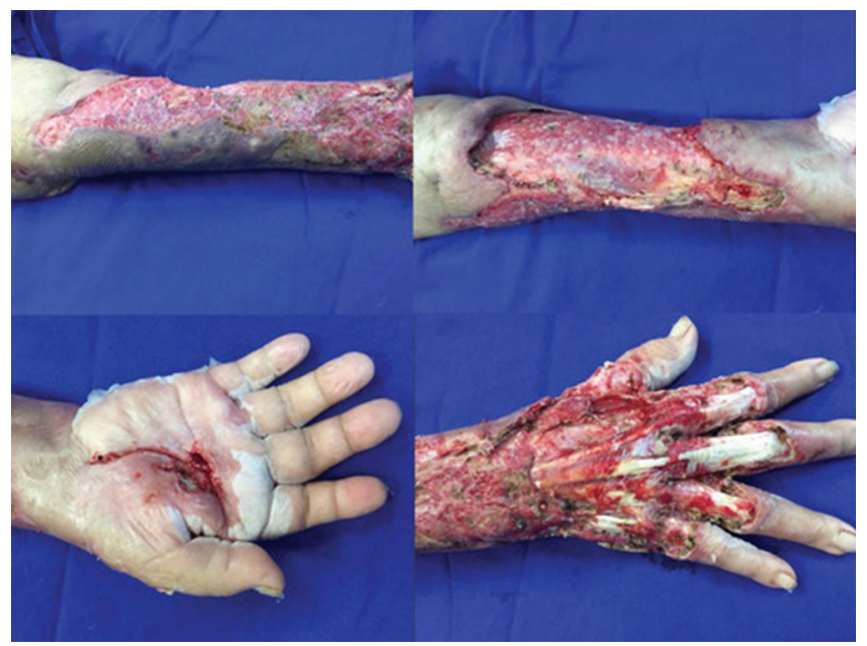

Figura 1. Lesão por extravasamento em dorso de mão e antebraço: lesão inicial extensa com exposição de tensões extensores do dorso da mão, evidenciando a necessidade de cobertura cutânea espessa por meio de retalho. 


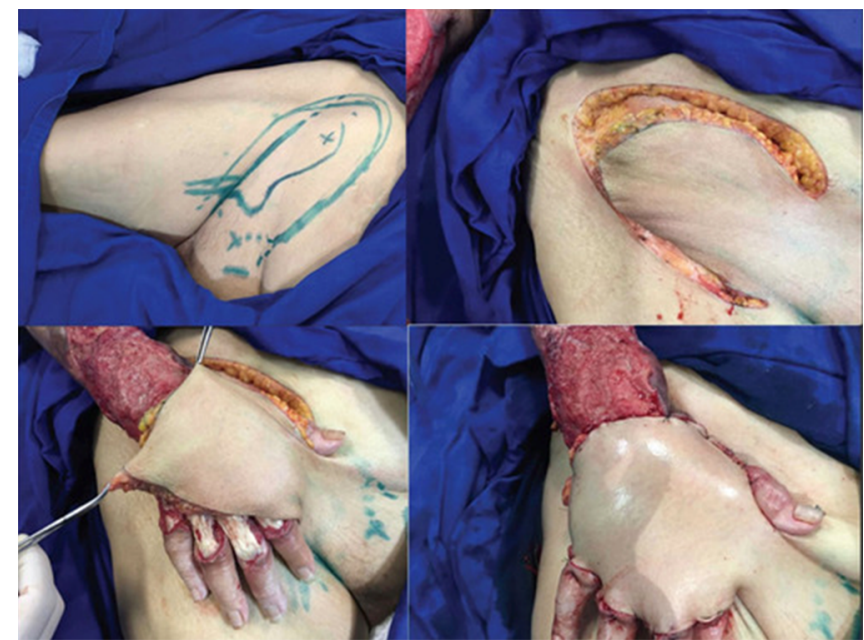

Figura 2. Paciente submetido à realização de retalho inguinal pediculado com cobertura adequada do dorso a mão, sem exposição tendínea ou de outras estruturas nobres.

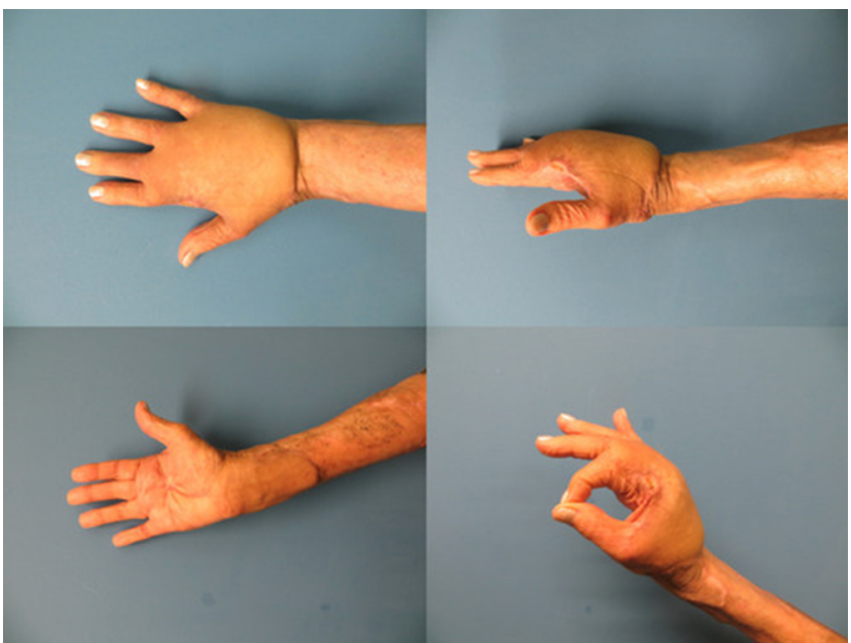

Figura 3. Resultado estético e funcional após seis meses da realização de retalho inguinal para o dorso da mão direita e enxerto de pele parcial em antebraço.

pressão negativa (Figura 4). O paciente evoluiu sem complicações em relação à ferida operatória e sem limitações da mobilização do membro.

O terceiro caso em que foi necessária a realização de retalho decorreu de extravasamento de droga não identificada em dorso da mão direita, tendo-se optado por retalho local romboide após uma semana de terapia por pressão negativa (Figura 5). A cobertura cutânea foi satisfatória para a cobertura dos tendões do dorso da mão e sem limitações.

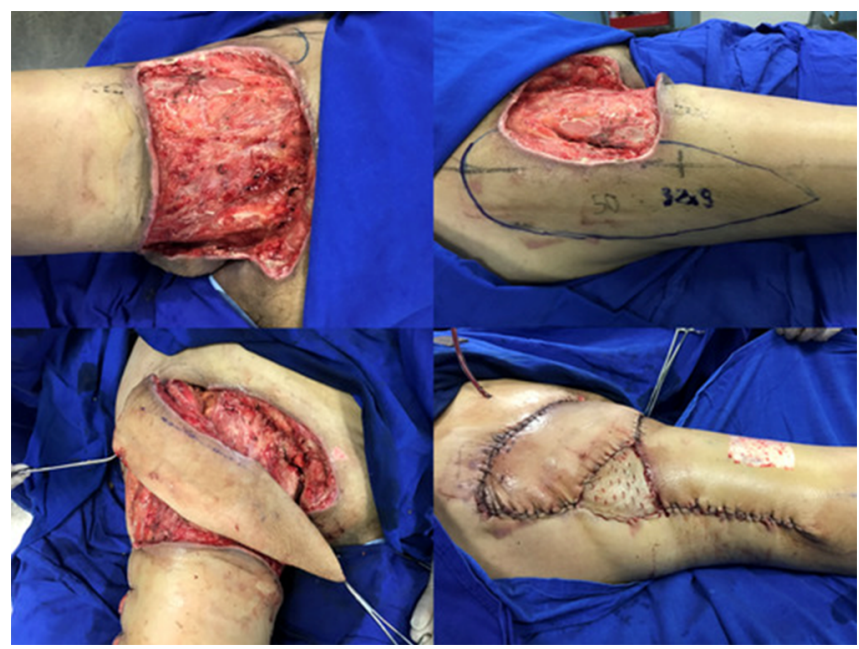

Figura 4. Realização de retalho tensor da fáscia lata para cobertura de região inguinal direita, submetida previamente a desbridamento e terapia por pressão negativa, necessitando de pequeno enxerto de pele parcial em área doadora do retalho.

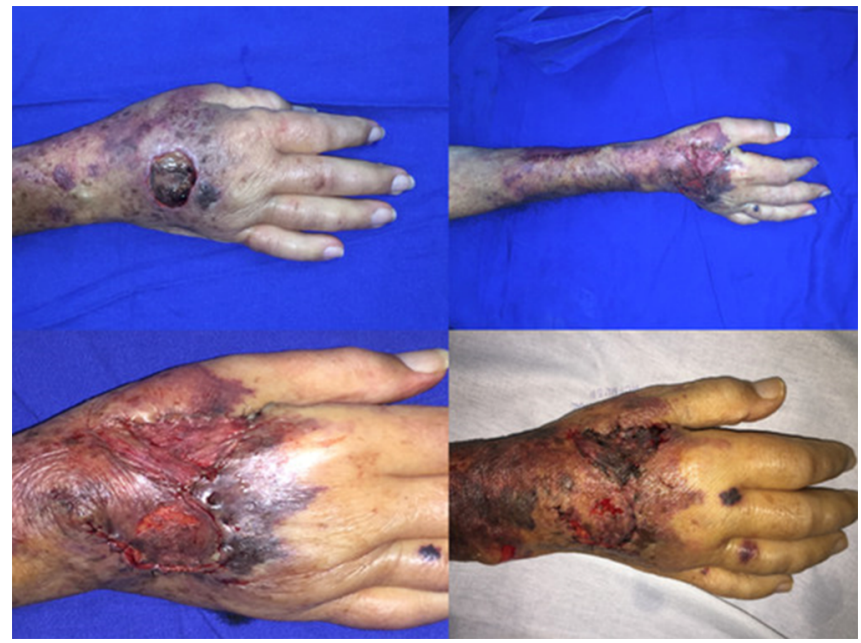

Figura 5. Realização de retalho local romboide (Limberg) em dorso da mão direita. No canto superior esquerdo, lesão ulcerada inicial, tratada por meio de desbridamento e curativo a vácuo, permitindo a realização de retalho local com boa cobertura da lesão.

\section{DISCUSSÃO}

A incidência de casos de extravasamento de drogas na literatura é subestimada, já que a maioria não é relatada ${ }^{7,8}$. A maior parte destes eventos ocorre à noite e não são percebidos, e o risco é aumentado quando pessoas inexperientes estão manipulando os acessos intravenosos, especialmente quando 
se utilizam drogas citotóxicas ${ }^{8}$. Possivelmente, o número de eventos ocorridos em nosso Serviço seja maior do que o observado, tendo em vista que apenas um dos casos não necessitou de desbridamento cirúrgico para a remoção de tecido necrótico. Assim, provavelmente a avaliação da Cirurgia Plástica foi solicitada apenas para os casos mais graves.

Os locais mais frequentemente envolvidos em casos de extravasamento de drogas são o dorso da mão e do pé, tornozelo, fossa antecubital, próximo a articulações ou espaços articulares, áreas com pouco tecido subcutâneo para proteção das estruturas subjacentes ${ }^{8,9}$.

Na casuística apresentada, o principal agente responsável pelas lesões por extravasamento foi a noradrenalina, sendo que em dois dos três casos estava sendo administrado em veia periférica. Os principais fatores de risco de necrose por extravasamento de drogas vasopressoras é a presença de doenças vasculares, hipotensão, neuropatia diabética, doença de Raynauld, coagulopatia, idade avançada e estado mental alterado ${ }^{10}$. Além disso, outro fator de risco importante é a administração em pequenas veias periféricas ou de circulação lenta, como as da fossa antecubital e a veia safena. A taxa de necrose cutânea decorrente da administração periférica de noradrenalina chega a 46-60\%.

O rápido reconhecimento do evento adverso é fundamental para que sejam realizadas as medidas iniciais. O diagnóstico precoce é crítico para reduzir a extensão da lesão e os primeiros sintomas são dor, eritema e edema local, seguido por palidez, flictenas e discromia cutânea. A presença de dor é o sintoma mais importante para alertar a equipe acerca da ocorrência do extravasamento e a sua duração, referida pelos pacientes, indica a gravidade do evento ${ }^{8,11}$.

De imediato, após reconhecimento da lesão por extravasamento, deve ser interrompida a infusão da droga e tentada sua aspiração pelo acesso existente. Há um espectro de opções aceitáveis, como a imobilização e observação contínua, antídotos tópicos e injetáveis quando disponíveis técnicas de irrigação de subcutâneo, desbridamento cirúrgico precoce e fasciotomia, quando há a presença de sinais de síndrome compartimental ${ }^{12}$.

A intervenção cirúrgica para as lesões por extravasamento pode ser imediata ou tardia. O melhor momento e o tipo de intervenção cirúrgica necessária em lesões por extravasamento ainda permanece controverso, tendo em vista a variedade de agentes causadores das lesões e as características dos pacientes nos estudos 3,13,14. Embora alguns autores defendam a intervenção cirúrgica precoce, em até 24 horas após ocorrência do evento, para evitar ulceração, necrose e infecção secundária, a maioria recomenda uma conduta inicial conservadora ${ }^{14,15}$. Entretanto, o tratamento cirúrgico pode ser necessário precocemente e sua indicação pode ser classificada em três situações: emergência (comprometimento neurovascular ou suspeita de síndrome compartimental); urgência (dor persistente, necrose em plano total e sepse de foco cutâneo) e eletivo (ulceração, não aderência ao tratamento com uso de curativos, atraso para tratamento da doença de base e cicatrização demorada) 3,16.

Concordamos que, inicialmente, todos os casos de extravasamento identificados devem ser tratados através de observação frequente e de métodos conservadores. Tais medidas incluem elevação do membro acometido, agentes emolientes, anti-inflamatórios e analgésicos, compressas geladas (ou aquecidas se catecolaminas ou alcaloides derivados da vinca), sendo a cirurgia reservada às situações citadas anteriormente, e sempre que há delimitação do tecido necrótico, período que varia entre 24 horas e 14 dias $^{7}$. Dessa forma, baseamos nossa conduta cirúrgica definitiva em duas condições principais: presença de necrose ou não e nas condições clínicas e nutricionais do paciente (Figura 6). Em geral, damos preferência a realização de tratamento cirúrgico definitivo em pacientes com níveis de hemoglobina acima de $10 \mathrm{~g} / \mathrm{dl}$ e de albumina acima de 3,0g/dl. 


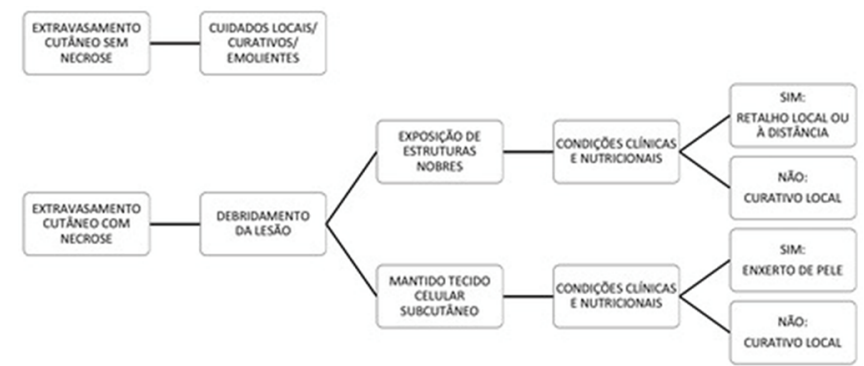

Figura 6. Fluxograma de conduta após lesão por extravasamento de droga, baseado na presença ou ausência de necrose e condições clínicas do paciente.

No estudo de Firat et al. ${ }^{7}$ foram avaliados 22 casos de extravasamento de drogas no período de dois anos, tendo evidenciado acometimento de membro superior na maioria dos casos (68\%), mais especificamente o dorso da mão. A maior parte dos casos foi de resolução cirúrgica, tendo sido resolvidos com enxertos (36,4\%) e retalhos $(27,3 \%)$. O fechamento da ferida por segunda intenção ocorreu em cinco casos e o tratamento conservador em três casos. O autor acredita que a conduta cirúrgica deve ser reservada para os casos de necrose cutânea em que haja indicação de procedimento cirúrgico, não intervindo precocemente nos casos de extravasamento.

Em geral, são necessários procedimentos cirúrgicos em cerca de um terço das lesões por extravasamento tratadas inicialmente de forma conservadora ${ }^{17}$. O desbridamento cirúrgico deve ser radical e realizado de modo a remover todo o tecido inviável, mantendo-se apenas o tecido não acometido e bem perfundido, observado pelo sangramento ativo no leito da ferida após a limpeza cirúrgica ${ }^{8}$. Muitas vezes, são necessários múltiplos desbridamentos nas semanas seguintes à ocorrência do extravasamento da droga, de modo a remover a necrose e o foco infeccioso. Nesses casos, os desbridamentos sequenciais são necessários até se obter um leito adequado para o fechamento definitivo da ferida por meio de enxerto ou retalho, aumentando o tempo de internação e os custos do tratamento ${ }^{15,18}$. Em nossos casos cirúrgicos com proposta de fechamento definitivo, foi utilizada a terapia por pressão negativa, que tem capacidade de redução das dimensões da ferida, remoção do fluido e de bactérias, redução do processo inflamatório local e estímulo ao tecido de granulação, colaborando com a melhora do leito da ferida ${ }^{19,20}$.

A cirurgia reconstrutora imediata ou tardia pode ser executada com resultados semelhantes ${ }^{21}$. Assim que houver indicação, o procedimento cirúrgico deverá ser executado o mais rapidamente possível, de modo a reduzir morbidade e não retardar o tratamento para a condição primária do paciente. Cedidi et al. ${ }^{22}$ compararam o tratamento cirúrgico precoce e tardio de lesões por extravasamento e observaram que todos os 18 pacientes encaminhados tardiamente (22 dias após o evento, em média) necessitaram de desbridamento, cobertura temporária da ferida, e definitiva, por meio de enxertos e retalhos. Este autor conclui que o encaminhamento precoce a um cirurgião plástico é necessário para a redução da necessidade de procedimentos cirúrgicos complexos, do risco de infecção, do tempo de tratamento e, consequentemente, dos custos.

$$
\text { Murphy et al. }{ }^{2} \text { avaliaram } 43 \text { casos de }
$$
lesões por extravasamento de drogas no período de 18 meses em hospital pediátrico da Austrália e encaminhados imediatamente após a identificação do evento para a equipe de Cirurgia Plástica. Observou-se a necessidade de irrigação de tecido subcutâneo em cinco pacientes (11\%) e apenas três (7\%) evoluíram com necrose cutânea. Essas lesões foram desbridadas e tratadas satisfatoriamente por meio de curativos com prata em sua composição, sem necessidade de cirurgias reconstrutoras, porém com aumento da morbidade e internação prolongada. Tal achado corrobora a conduta expectante em relação às lesões tratadas conservadoramente nos três casos aqui apresentados de pacientes pediátricos.

A utilização de protocolos bem estabelecidos de atendimento inicial após ocorrência 
de extravasamento e a utilização de medidas, como infiltração cutânea com solução salina, pode colaborar para a redução do número de casos que evoluem com necrose tecidual ${ }^{23}$. Na avaliação da ocorrência de extravasamento de drogas num período de 12 anos, por D' Andrea et al. ${ }^{24}$, foram evidenciados 240 casos. Destes, apenas 11 evoluíram com necrose e ulceração, necessitando de cobertura definitiva. Todas as lesões eram em dorso das mãos e foram tratadas por meio de enxerto em um caso, retalho local em quatro casos, retalho radial em outros quatro casos e retalho microcirúrgico músculo-cutâneo de serrátil em dois casos. Outra opção para os pacientes que têm lesão com exposição de estruturas nobres após desbridamento cirúrgico é a utilização de substitutos dérmicos, quando disponíveis.

Foi observado neste estudo que o tratamento definitivo por meio de retalhos se mostrou adequado para os casos de feridas por extravasamento de drogas em tecido subcutâneo quando há exposição de estruturas profundas em pacientes com condições clínicas favoráveis.

\section{A B S T R A C T}

Objective: to report the experience of the Division of Plastic Surgery of the Hospital das Clinicas of the Medical School of the University of São Paulo in the treatment of cutaneous lesions due to accidental extravasation of drugs. Methods: we included patients with lesions due to extravasation of drugs over a period of 18 months. We retrospectively evaluated the following parameters: age, diagnoses during hospitalization and comorbidities, serum levels of albumin and hemoglobin, place of hospitalization, drug involved, anatomic segment affected, therapeutic management and death during hospitalization. Results: we followed-up 14 patients. The main drug involved was noradrenaline (21\%). All patients underwent debridement of tissue necrosis. Three patients were submitted to flaps after preparation of the wound bed with negative pressure therapy, with good results. Seven patients had no definitive treatment of their lesions due to lack of clinical conditions. Conclusion: in patients with favorable clinical conditions, the definitive treatment with flaps was adequate for cases of wounds due to extravasation of drugs in the subcutaneous tissue when there was exposure of noble structures.

Keywords: latrogenic Disease. Extravasation of Diagnostic and Therapeutic Materials. Ischemia. Necrosis. Surgical Flaps. Surgery. Plastic.

\section{REFERÊNCIAS}

1. Reynolds PM, MacLaren R, Mueller SW, Fish DN, Kiser TH. Management of extravasation injuries: a focused evaluation of noncytotoxic medications. Pharmacotherapy. 2014;34(6):617-32.

2. Murphy AD, Gilmour RF, Coombs CJ. Extravasation injury in a paediatric population. ANZ J Surg. 2017 Jul 6. doi: 10.1111/ans.

3. Goutos I, Cogswell LK, Giele H. Extravasation injuries: a review. J Hand Surg Eur Vol. 2014;39(8):808-18.

4. Tong R. Preventing extravasation injuries in neonates. Paediatr Nurs. 2007;19(8):22-5.

5. Bhananker SM, Liau DW, Kooner PK, Posner KL, Caplan RA, Domino KB. Liability related to peripheral venous and arterial catheterization: a closed claims analysis. Anesth Analg. 2009;109(1):124-9.

6. Le A, Patel S. Extravasation of noncytotoxic drugs: a review of the literature. Ann Pharmacother. 2014;48(7):870-86.
7. Firat $\mathrm{C}$, Erbatur $\mathrm{S}$, Aytekin $\mathrm{AH}$. Management of extravasation injuries: a retrospective study. J Plast Surg Hand Surg. 2013;47(1):60-5.

8. Al-Benna S, O'Boyle C, Holley J. Extravasation injuries in adults. ISRN Dermatol. 2013;2013:856541.

9. Garden AL, Laussen PC. An unending supply of 'unusual' complications from central venous catheters. Paediatr Anaesth. 2004;14(11):905-9.

10. Chen JL, O'Shea M. Extravasation injury associated with low-dose dopamine. Ann Pharmacother. 1998;32(5):545-8.

11. Heckler FR. Current thoughts on extravasation injuries. Clin Plast Surg. 1989;16(3):557-63.

12. Hannon MG, Lee SK. Extravasation injuries. J Hand Surg Am. 2011;36(12):2060-5.

13. Wickham R, Engelking C, Sauerland C, Corbi D. Vesicant extravasation part II: Evidence-based management and continuing controversies. Oncol Nurs Forum. 2006;33(6):1143-50. 
14. Boulanger J, Ducharme A, Dufour A, Fortier S, Almanric K; Comité de l'évolution de la pratique des soins pharmaceutiques (CEPSP); Comité de l'évolution des pratiques en oncologie (CEPO). Management of the extravasation of anti-neoplastic agents. Support Care Cancer. 2015;23(5):1459-71.

15. Schulmeister L. Extravasation management: clinical update. Semin Oncol Nurs. 2011;27(1):82-90.

16. Fallscheer $P$, Kammer E, Roeren $T$, Meuli-Simmen $C$. Injury to the upper extremity caused by extravasation of contrast medium: a true emergency. Scand J Plast Reconstr Surg Hand Surg. 2007;41(1):26-32.

17. Kassner E. Evaluation and treatment of chemotherapy extravasation injuries. J Pediatr Oncol Nurs. 2000;17(3):135-48.

18. Ener RA, Meglathery SB, Styler M. Extravasation of systemic hemato-oncological therapies. Ann Oncol. 2004;15(6):858-62.

19. Anghel EL, Kim PJ. Negative-pressure wound therapy: a comprehensive review of the evidence. Plast Reconstr Surg. 2016;138(3 Suppl):129S-37S.

20. Milcheski DA, Ferreira MC, Nakamoto HA, Pereira DD, Batista BN, Tuma P Jr. Subatmospheric pressure therapy in the treatment of traumatic soft tissue injuries. Rev Col Bras Cir. 2013;40(5):392-6.
21. Shenaq SM, Abbase EH, Friedman JD. Softtissue reconstruction following extravasation of chemotherapeutic agents. Surg Oncol Clin N Am. 1996;5(4):825-45.

22. Cedidi C, Hierner R, Berger A. Plastic surgical management in tissue extravasation of cytotoxic agents in the upper extremity. Eur J Med Res. 2001;6(7):309-14.

23. Napoli P, Corradino B, Badalamenti G, Tripoli M, Vieni $S$, Furfaro MF, et al. Surgical treatment of extravasation injuries. J Surg Oncol. 2005;91(4):264-8.

24. D'Andrea F, Onesti MG, Nicoletti GF, Grella E, Renzi $L F$, Spalvieri $C$, et al. Surgical treatment of ulcers caused by extravasation of cytotoxic drugs. Scand J Plast Reconstr Surg Hand Surg. 2004;38(5):288-92.

Recebido em: 15/05/2018

Aceito para publicação em: 29/05/2018

Conflito de interesse: nenhum.

Fonte de financiamento: nenhuma.

\section{Endereço para correspondência:}

Dimas André Milcheski

E-mail: dimas.milcheski@hc.fm.usp.br drdimasandre@gmail.com 